tributions to the science of fibre structure, especially collagen.

The symposium on "The Fine Structure of Viruses" arranged by Dr A. F. Howatson (Medical Biophysics Department, University of Toronto, Toronto 5, Ontario) was especially noteworthy in that the presentation of papers on recent advances in fine structure, animal virus structure, electron microscopy of nucleic acids and proteins, structures of bacteriophages and their variations, and work on the fine structure of foot-and-mouth disease virus brought together in a very logical sequence the information on the recent improvements in the techniques of replication, shadow-casting, thin sectioning and "negative contrast" staining and their application and interrelationships in obtaining new information on the structure of viruses both in situ and isolated.

\section{Fifth International Congress for Electron Microscopy}

Arrangements for the Fifth International Congress for Electron Microscopy to be held in Philadelphia during August 29-September 5, 1962, were announced at the meeting.
The Electron Microseope Society of America will be the host for the International Federation of Electron Microscope Societies at this Congress to be held, coincidently, on the twentieth anniversary of the Electron Microscope Society of America. Efforts are being made to have the Congress include the most significant developments since the last Congress in Berlin in 1958. The general theme will emphasize new and unique contributions of electron microscopy toward the advancement of science. In addition to contributed papers, the programme is being organized to include special papers by invited speakers which will set the theme of each session. In the interest of the earliest possible dissemination of the new material to be presented at the Congress, the Committee has completed arrangements for each active member at the Congress to receive the bound copy of the scientific papers at the time of registration. This will contain an abbreviated paper, including some micrographs or illustrations, for each scientific contribution presented at the Congress.

Further information can be obtained from the Secretary, Fifth International Congress for Electron Microscopy, 7701 Burholme Avenue, Philadelphia 11, Pennsylvania.
A. R. TAYLOR

\title{
THERMIONIC CONVERSION OF HEAT TO ELECTRICITY
}

\begin{abstract}
SYMPOSIUM on the thermionic generation of electricity was held at Bankside House, London, on May 11. It was organized by the Central Electricity Generating Board and attended by workers in the field of thermionic generation from a number of public and private concerns in Britain.

An opening address by Dr. K. H. Spring, of the Research and Development Department of the Central Electricity Generating Board, was followed by a paper from Mr. R. V. Harrowell, also of the Board, and Dr. J. Myatt (Atomic Energy Research Establishment, Harwell) on the efficiency and power of a diode generator. This paper examined the simplified expression for efficiency:
\end{abstract}

$$
\eta=\frac{\varphi_{c}-\varphi_{A}}{\varphi_{c}+P_{L} / I_{A}}
$$

where $\varphi_{c}$ and $\varphi_{A}$ are cathode and anode work functions, $P_{L}$ is the power loss and $I_{A}$ is the anode current. When $\eta$ is plotted against $\varphi_{c}$, the resulting humped curve is asymptotic to zero efficiency as $\varphi_{c}$ is increased indefinitely; and for $\varphi_{c}=\varphi_{A}, \eta=0$. It was pointed out that emphasis is seldom laid on the fact that this efficiency curve is valid only for a matched load at each value of $\varphi_{c}$ : it is then true that $\eta=0$ at $\varphi_{c}=$ $\varphi_{A}$. But it is quite possible, under non-matched conditions, to have a high efficiency even when $\varphi_{c}=$ $\varphi_{A}$, and this, or an intermediate state, may be desirable in certain circumstances. More important is the fact that, under matched conditions, maximum efficiency may sometimes be sacrificed for an increase in power; in this case $\varphi_{c}$ will be less than its value at maximum efficiency.

A low anode work-function is important for the realization of high efficiency. The effective workfunction of a metal anode in cæsium vapour depends on the cæsium coverage of the surface. A value below both the figure for clean metal and the bulk cæsium work-function can be achieved with a correct balance between the anode temperature and the saturated cæsium temperature: a value of $1.1 \mathrm{~V}$. has been quoted.

A study of the work-functions of anodes opposite oxide cathodes has been made by Dr. B. J. Hopkins (University of Southampton). The work-function of a clean nickel anode $(\sim 4 \cdot 7$ V.) fell to less than $2.5 \mathrm{~V}$. when the cathode was in the most active condition. Dr. Hopkins considers that barium oxide evaporates from the cathode in the molecular form and is deposited on the anode. Three methods of measurement were used : two depend on the determination of the contact potential difference from retarding field curves; the other uses the contact potential difference obtained by the Kelvin method. If the contact potential difference between the cathode and a known reference surface is also measured, then the anode work-function can be found by eliminating the cathode work-function from the two expressions; alternatively, the cathode work-function can be measured from a Richardson plot, although this would give a less trustworthy result.

Mr. D. C. Gore (Central Electricity Generating Board) read a paper entitled "The Thermionic Diode in Large-Scale Power Production from Fossil Fuels". This dealt with the diode as a thermodynamic topping device in a conventional boiler, using the upper part of the available temperature-range, which is not usable in a steam cycle. The mechanical arrangement would be for the diodes, in cylindrical form, to envelop the boiler tubes; the outer, cylindrical cathodes would be heated by the furnace gases. If a diode efficiency of 20 per cent could be attained and the efficiency of the conventional plant were 35 per cent, the total plant efficiency would be raised to 45 per cent by the introduction of diode 'toppers' passing three-quarters of the available heat. Any saving in fuel costs would probably be considerably offset by the relatively short life of the diodes, but Mr. Gore believes that if the very difficult problems of materials can be solved there are reasonable prospects for reducing generating costs. Some of the problems 
of materials and techniques were then reviewed by Mr. E. Cohen (Central Electricity Generating Board).

Mr. D. A. Watt (Atomic Energy Research Establishment, Harwell) and Mr. J. A. McWilliams (Boucher and Co., Kidderminster) described two engineering design studies of experimental in-pile thermionic generators: one has a planar geometry and uses ceramic-metal seals; the other, with a cylindrical geometry, has been simplified by omitting the ceramic-metal seals and using a continuous stainless steel envelope, which also forms the anode load. In the planar device the cathode is a coating of natural or depleted uranium carbide-zirconium carbide $(25: 75)$ on a tantalum 'top-hat', the inside of which contains uranium carbide-zirconium carbide enriched with uranium-235 as the fuel. To overcome the serious compatibility problem of fuel material in contact with tantalum at $2,000^{\circ} \mathrm{C}$., the cylindrical version uses a rod of uranium carbide-zirconium carbide made of depleted or natural material at the end in contact with the tantalum cathode support and enriched material as the fuel at the free end. An output of about $300 \mathrm{~W}$. was expected from an experimental model of the cylindrical diode being made.

The use of ion injection for space charge neutraliza. tion was discussed in a paper by Mr. G. G. Isaacs (G.E.C. Hirst Research Centre). In this type of device, ions are generated by an auxiliary discharge and, therefore, inert gases may be used instead of the chemically active alkali metal vapours. The experiments reported indicated a high degree of neutralization of space charge. A net output of about $200 \mathrm{~mW}$. was obtained at an efficiency of about 1 per cent; however, no attempt had been made to optimize the design. As well as freedom of choice of filling gas, a further advantage of this kind of device is its potentiality for generating alternating current.

Mr. J. A. Thorp (A.E.I., Rugby) spoke on "Auxiliary Ion Sources in Cæsium Diodes". One method of neutralization of space charge is to produce positive ions from cæsium atoms in contact with a hot surface the work-function of which exceeds the ionization potential of cæsium. Mr. Thorp dealt with an investigation using matrix-type cathodes of low average work-function but with some high work-function spots at which ionization occurs. It is possible, however, for some ions to be trapped in a potential well at the mixed work-function surface and thereby be rendered ineffective. In the work described, a hot tungsten filament between anode and cathode has been used to ionize the cæsium. When the filament was biased one or two volts positive relative to the cathode, the anode current was several times greater than when the ionizer was unbiased. This indicated that the potential well at the filament was removed and positive ions were released.

In an analysis of the processes of ionization and de-ionization in a diode, Dr. L. G. Sanders (Atomic Energy Research Establishment, Harwell) considered the comparative effects of ionization by electron collisions and photons, and the so-called resonance ionization (also used by Mr. Thorp). It appears that the first two types of ionization are small compared with resonance ionization at the eathode, provided, in the case of electron collisions, that the electrons are at cathode temperature. However, if the electrons are at a temperature two or three times greater than the cathode temperature of about $2,000^{\circ} \mathrm{C}$., electron collision ionization can make an appreciable contribution. The electron temperature may well be of this order due to barrier and Thomson heating. A simple approach, based on the current balance at the electrodes, has shown that the highest vapour pressure necessary is that which just noutralizes the negative space charge. If the pressure has to be higher than this amount in order to lower the cathode work-function by partial cæsium coverage, then the electrode spacing should be decreased to limit the plasma resistance.

In a review of progress in the United States, Dr. B. C. Lindley (C. A. Parsons and Co., Ltd.) reported that the trend there is towards the use of refractory metal cathodes and high cæsium pressures: the former enables high cathode temperatures to be used, while the high vapour pressure $(\sim 10 \mathrm{~mm}$. mercury) ensures, even at $2,000^{\circ} \mathrm{C}$., a reduction in work-function due to the presence of a monolayer of exsium; electrode spacings of the order of the electron mean free path minimize heat conduction through the plasma. Most of the American groups visited were working on the close-spaced vacuum converter as well as the cæsium version.

"The Crossed Field Thermionic Converter" was the title of the final paper, which was read by Dr. G. D. Sims (University College, London). In this device, space charge is overcome by crossed electric and magnetic fields. Dr. Sims described experiments that have established beam interaction with the accelerator electrode in the initial apparatus used. He believes there is little doubt that the accelerator current, which persists even with extremely high magnetic fields, arises as a result of instability in the electron cloud; this gives rise to either amplification of noise or oscillation-resulting in radio-frequency fields which cause electrons to lose sufficient energy to be drawn to the accelerator. This represents wasted power. Further experiments are being planned with the view of the suppression of accelerator current. R. V. HaRRoWELI.

\section{RESEARCH IN THE LEATHER INDUSTRY}

$\mathrm{T}$ HE seventh biennial conference of the International Union of Leather Chemists Societies was held in Washington, D.C., during August 20-25.

The International Union was founded in Europe after the second World War as a confederation of national member societies concerned with the leather industry, and research and technology related to it. From an early stage in its development, it had as one of its members the American Leather Chemists' Association, and in the twelve years since its foundation it has come to include among its twenty-five member societies a steadily increasing number from Asia, Africa and South America, the expanding leather industries of which are based on locally available supplies of hides, skins and tanning materials. The decision to hold this year's biennial conference outside Europe for the first time, and to combine it with the annual meetings of the American Leather Chemists Association, is evidence of the growing collaboration between American and European leather chemists and their colleagues in other continents. Thanks to its efficient organization by the host society, 